Clio. Femmes, Genre, Histoire

1 | 1995

Résistances et Libérations France 1940-1945

Une prise de conscience féministe ? L'Occupation vue par les femmes écrivains en France après 1968

\title{
Claire GORRARA
}

\section{(2) OpenEdition}

1 Journals

Édition électronique

URL : https://journals.openedition.org/clio/525

DOI : $10.4000 /$ clio. 525

ISSN : 1777-5299

Éditeur

Belin

Édition imprimée

Date de publication : 1 avril 1995

ISSN : 1252-7017

Référence électronique

Claire GORRARA, «Une prise de conscience féministe ? L'Occupation vue par les femmes écrivains en France après 1968 », Clio. Femmes, Genre, Histoire [En ligne], 1 | 1995, mis en ligne le 01 janvier 2005, consulté le 23 avril 2022. URL : http://journals.openedition.org/clio/525 ; DOI : https://doi.org/ 10.4000/clio.525

Ce document a été généré automatiquement le 23 avril 2022.

Tous droits réservés 


\title{
Une prise de conscience féministe? L'Occupation vue par les femmes écrivains en France après 1968
}

\author{
Claire GORRARA
}

1 1994, cinquantième anniversaire de la libération de la France, 1995, cinquantième anniversaire de la libération des camps de concentration et de la fin de la guerre en Europe ; toutes ces commémorations nous montrent l'importance de la mémoire de la Deuxième Guerre mondiale sur l'identité politique et culturelle des peuples européens. Néanmoins, l'historien et le critique littéraire ont souvent du mal à trouver des témoignages de femmes relatant l'Occupation. Pourtant, beaucoup de femmes ont évoqué leurs souvenirs de guerre au cours de ces vingt-cinq dernières années, sous forme d'autobiographie, de roman ou de journal intime. Il suffit d'analyser ces récits pour mesurer l'importance de l'Occupation et pour la percevoir comme une période historique qui apporte aux femmes une véritable "prise de conscience " de leur identité féminine.

2 Cette prise de conscience est liée intimement à l'avènement du féminisme des années 1970 qui a encouragé ces femmes à réinterpréter leurs expériences à la lumière des idées révolutionnaires comme "the personal is the political ». Ce mouvement politique et culturel a touché des femmes de deux générations de manière différente. En effet, il a permis aux "résistantes », celles qui ont vécu la guerre comme adulte résistante, et aux «filles de l'Occupation ", celles qui ont vécu la guerre comme enfant, de mieux comprendre leurs rélations avec l'histoire troublée des " années noires ».

3 En premier lieu, il faut considérer les récits des résistantes. Ces femmes ont tendance, dans les années 1970, à écrire des témoignages qui s'engagent dans le combat contre les mensonges des «négationnistes ». Le procès de Klaus Barbie en 1987 a déclenché une vague d'autobiographies qui présentaient une image plutôt glorieuse de la Résistance, par exemple Le Sel de la mine de Raymonde Guyon-Belot. Ces récits ne comportaient pas d'analyse directe de la position, quelquefois difficile, des femmes dans la Résistance et ce pour éviter de faire apparaître des divisions internes. Celles-ci auraient pu, en effet, 
servir d'armes pour ceux qui soutenaient la cause de Barbie et les collaborateurs français. Néanmoins, quelques résistantes de cette génération ont insisté sur le fait que les femmes ont vécu la Résistance autrement à cause de leur sexe. L'une de ces femmes est Lucie Aubrac qui a dépeint une image frappante des femmes sous l'Occupation dans son livre Ils partiront dans l'ivresse.

L'originalité du livre de Lucie Aubrac vient de sa décision de structurer le récit de ses activités résistantes au travers des neuf mois de sa grossesse. Lucie était enceinte de six mois quand elle a fait évader son mari, Raymond Aubrac, de la prison de Montluc à Lyon. Le personnage autobiographique de Lucie Aubrac est toujours conscient du fait que sa condition de femme enceinte lui donne l'opportunité de duper à la fois les autorités françaises et la Gestapo qui ne soupçonnaient pas l'importance de son rôle de résistante, aveuglées par une image stéréotypée des femmes. Toutefois, la narratrice est consciente aussi du fait qu'être femme lui pose un problème avec certains résistants qui refusent soit de valoriser ses actions, soit de lui accorder une place légitime dans leur groupe en tant que femme, ne l'acceptant qu'à titre honorifique. En mettant l'emphase sur son identité féminine et maternelle, Lucie Aubrac, comme Cécile Ouzoulias Romagon dans J'étais agent de liaison des FTPF, essaie de détruire le mythe des femmes, « héroïnes exceptionnelles de la Résistance ». Elle le remplace par des images de femmes qui, au jour le jour, ont réussi à réconcilier leurs rôles de femme au foyer, de mère et de résistante. Même s'il n'est pas possible de déceler des thèses féministes très développées dans son livre, Lucie Aubrac nous montre comment certaines résistantes, dans les années 1980, ont publié des récits, avec une perspective ante-féministe, des conditions de combat des femmes.

En revanche, les femmes-écrivains de la deuxième génération, celles qui ont vécu la guerre comme enfant ou qui sont nées aprés la Libération, présentent une vision de l'Occupation influencée par des débats féministes des années 1970. L'une de ces écrivains est Evelyne Le Garrec, fille d'un membre du PPF de Doriot. Elle caractérise son récit, $L a$ Rive allemande de ma mémoire, comme un "auto-reportage" où elle essaie d'explorer à la fois son enfance traumatisée et la collaboration de son père, tué devant sa maison par des résistants. Avant tout, elle voulait exorciser ses sentiments de culpabilité quant à ses liens familiaux avec la collaboration et l'extermination des juifs. Mais plus elle s'engouffre dans le passé en quête de son père, plus elle se rend compte qu'elle ne peut pas accepter cet oppresseur qui lui faisait peur et qui, au moment d'écrire son livre à la fin des années 1970, représentait la tyrannie du patriarcat dans la société occidentale.

6 Pour combattre l'effet néfaste de ce père maudit, l'écrivain s'en rapporte à son héritage maternel : la vie de sa mère et de sa grand-mère maternelle allemande qui n'ont pas eu de voix dans l'histoire familiale jusqu'à présent. Evelyne Le Garrec découvre leurs vies secrètes; leur refus d'accepter le nazisme qui promouvait les vertus de Kinder, Küche, Kirche, ainsi que leur rejet des sentiments nationalistes. Pour renforcer cette perspective féminine et féministe de l'Occupation, Evelyne Le Garrec recrée aussi la vie des Espagnoles républicaines exilées, symbolisées par la rebelle communiste, $L a$ Pasionaria. Ces femmes étaient à l'opposé de l'idéologie fasciste que soutenait son père, collaborateur zélé, et elles donnent aux lecteurs et lectrices l'image de femmes marginalisées qui représentent en quelque sorte, pour l'écrivain, la position des féministes dans la société moderne. 
7 En conclusion, ce que montrent ces deux générations de femmes, c'est l'importance de l'Occupation comme point de repère des réinterprétations féministes de l'histoire française. Pour les résistantes de la première génération, l'Occupation et la vie clandestine leur ont fourni l'occasion de remettre en question des idées reçues sur le rôle et les capacités des femmes dans la vie moderne. Tandis que pour les filles de l'Occupation, les analyses féministes des années 1970 leur ont permis de dénoncer les préjugés sexistes que sous-tendait l'idéologie de la collaboration. Il nous faut étudier de tels récits pour entendre ces voix perdues et pour enrichir notre connaissance d'une période qui continue à hanter la France contemporaine.

\section{BIBLIOGRAPHIE}

Note bibliographique : cette présentation sommaire est tirée de ma thèse de doctorat qui s'entitule A Woman's Occupation : French Women's Writing and Representations of the Occupation in Post-1968 France, soutenue à Lincoln College, Oxford University, September 1994. Les principaux récits utilisés dans mes recherches sont les suivants :

Mireille Albrecht, La Grande figure féminine de la Résistance - Berty (Laffont, 1986)

Lucie Aubrac, Ils partiront dans l'ivresse (Seuil, 1984)

Sophie Aurel, Petites chroniques versaillaises sous la guerre et l'occupation (La Pensée Universelle, 1989)

Jeanne Bohec, La Plastiqueuse à bicyclette (Mercure de France, 1975)

Marie Chaix, Les Lauriers du lac de Constance (Seuil, 1974)

Marguerite Duras, La Douleur (P.O.L., 1985)

Brigitte Friang, Regarde-toi qui meurs (Plon, 1970)

Dominique Garnier, Nice, pour mémoire (Seuil, 1980)

Marie Gatard, La guerre, mon père (Mercure de France, 1978)

Benoîte et Flora Groult, Journal à quatre mains (Denöel, 1962)

Annie Guéhenno, L'Epreuve (Grasset, 1968)

Raymonde Guyon-Belot, Le Sel de la mine (Editions France-Empire, 1990)

Annette Kahn, Robert et Jeanne à Lyon sous l'Occupation (Payot, 1990)

Evelyne Le Garrec, La Rive allemande de ma mémoire (Seuil, 1980)

Clara Malraux, La Maison ne fait pas crédit (1947), La Lutte inégale (Julliard, 1958), Le Bruit de nos pas, Vols 5\&6 (Grasset 1976, 1979)

Violette Maurice, Les Murs éclatés (Action Graphique Editeur, 1990)

Frédérique Moret, Journal d'une mauvaise Française (La Table Ronde, 1973)

Cécile Ouzoulias-Romagon, J'étais agent de liaison des FTPF (Editions Messidor, 1988) 
Michèle Ramond, L'Occupation (Editions des femmes, 1991) 